\title{
Opportunities and Challenges Faced in Social Governance Innovation under the Background of Lobalization
}

\author{
Chen Meixia \\ School of Finance and Public Management, \\ Yunnan University of Economics and Finance,Kunming,P.R.China 650221 \\ yngcx@126.com
}

\begin{abstract}
Under the background where overlapping, crossing and reorganization of old and new mechanisms to different extent in different regions and countries in the world, new changes have taken place in the situation of social governance. New issues and challenges faced in social governance must be studied and analyzed in order to strengthen and innovate on social governance and maintain harmony and stability of the global society. To deal with such new challenges, it not only requires that we have deeper and acuter insight into the globalization trend impacting the future, but it also requires that we continuously break the limitation of traditional thinking framework to improve our judgment over social governance and our capacity of transforming challenges with the imagination of more innovative thoughts, thus to create the new global layout of social governance of co-development, co-governance and sharing.
\end{abstract}

Key words-globalization; social governance; innovation; co-development co-governance and sharing

\section{INTRODUCTION}

For social governance, under the background of globalization, social governance innovation at the critical stage of the new era of all-people co-development and sharing and the decisive stage of building a moderately prosperous society in all aspects further specifies that social governance is a process of common participation by all the people instead of the simple relation of managing and being managed. From social administration to social governance to the social governance of all-people co-development and sharing, and to the new layout of social governance of co-development, co-governance and sharing, it not only reflects the continuous improvement and gradual maturity of the understanding about social governance, but it also contains the essential requirements of social governance.

It is safe to say that the evolution of social governance layout contains the sublimation of ideas, transforms the way of innovation, builds the new system and shows the new image.

\section{IMPORTANCE AND URGENCY OF SOCIAL GOVERNANCE}

INNOVATION UNDER THE BACKGROUND OF GLOBALIZATION

Social governance innovation mainly refers to the process of conforming to the requirements of social development, integrating new theories, experience and technologies, respecting the rules of social operation and promoting the transformation in the idea, normal form, mechanism, method and path of social governance, thus to realize the mode transformation from traditional social administration to social governance to stimulate social vitality, improve the efficiency of governance and promote benign social development. Presently, we are stepping into a new age of global affairs, and innovation on social governance is extremely important and urgent.

\section{A. Social Governance Innovation Is the Intrinsic}

Requirement of Social Development

In the new era, tides of globalization, market orientation, urbanization and informatization have upsurged in an overlapped manner, with various changes taking place in situation of the world, China and the society, social interests 
highly differentiated, social structure changed in a higher speed, social driving force and vitality significantly improved and profound changes taking place in the social environment. With deepening of the reform, traditional social ideas, social order and lifestyle will be challenged, with higher requirements proposed for the idea and level of social governance. The understanding about social form and social administration system is more profound, which will propose challenge against the traditional social governance. At such a moment, social governance innovation is particularly urgent.

\section{B. Social Governance Innovation Is the Urgent Need of}

\section{Settling Social Conflicts and Issues}

Social governance innovation is an important means of improving social stability and maintaining national interests. Presently, reform in China has entered the crucial stage and development entered a critical period, with social conflicts arising in a large number and scale. Some conflicts are highly correlated, likely to change, sensitive and antagonistic, with prominent issues concerning the people's immediate interests. China is in a period of both important strategic opportunity for development and prominent social conflicts. China is in the tide of economic globalization as well as an environment with complicated and changeable international situation. Therefore, social governance innovation is urgently necessary to settle the complicated social conflicts and issues.

\section{Social Governance Innovation Is to Promote the Wish of} the Human Beings for Co-Development, Reciprocity and Co-win

In order to cohere, manifest and develop common interests of the human beings, we must promote mutual integration of interests of various countries, regions and international behavior subjects. Promoting social governance innovation, realizing co-development of the human beings and upholding the global governance philosophy of co-consultation, co-development and sharing is in response to the historical tide of globalization to promote the construction of new international relations of mutual respect, equality, justice, cooperation and co-win. Relying on the mass power to opening social participation and jointly promote social governance innovation is what the people want.

\section{Social Governance Innovation Is to Propose Higher}

\section{Appeal for Public Service}

The core of social governance of service for and management of people. Benign social operation, harmonious development and effective social governance require a set of scientific and reasonable basic system as a security to ensure the mechanism and method to play their role. For fostering of a social governance layout of co-development, co-governance and sharing in the new era, sharing is the purpose, while co-development and co-governance is the means. Co-development is the key point and precondition, while co-governance is the key and security. Co-development and co-governance is mutually supplementary and conditional, serving the fundamental purpose of sharing. Co-development, co-governance and sharing is the lively embodiment and specific requirement of the people-centered idea. Therefore, promoting social governance innovation is requirement of the era and what the people what as well as where mission of the government lies.

\section{BASIC APPROACHES OF SOCIAL GOVERNANCE}

\section{INNOVATION}

Realizing multivariate, bottom-up and bidirectional social governance and service and promoting the human beings to realize self-management, self-service, self-education and self-supervision in community governance, public service and public welfare undertakings is undoubtedly an effective way to explore and realize social governance capacity.

\section{A. Innovation on Governance Philosophy}

Philosophy is the fundamental value orientation, and promotion of social governance innovation must start with transformation of philosophy. The idea of people orientation and respecting individuals must be established to respect the basic rights, creativity and difference of social individuals, thus to implement different policies for different people and providing service for the people. The idea of multivariate subjects and cooperative governance must be established to specify the responsibility of each subject of governance, establish governance mechanism, accumulate social resources based on management and service and establish the system-based and legal governance idea, thus to reach the 
governance effect of "making decisions based on rules and stopping disputes by law".

\section{B. Innovation on Governance Method}

Necessary system and standard should be established to solve social conflicts through corresponding system arrangement and standard establishment and soundly deal with the relation between vitality and order. We shall insist systematic governance, governance by law, comprehensive governance and source governance with policies combining rigidness and flexibility to realize the transformation from single governance to co-governance, regulate social interests and maintain social order, thus to provide deep-level system security for overall harmonious and sustainable development of the society. Transformation should be realized from control and regulation to comprehensive of multiple methods such as moral direction, psychological counseling, conflict relief and legal security.

\section{Realize Compound Governance, Integrate Multivariate Subjects of Governance}

It is to further establish the layout of social governance, define the governance authority boundary of the government, enhance the responsibility of the market subject and the public to participate in governance, make the channels of social participation smooth, optimize the development environment of social organizations and gradually improve the self-governance ability of the society. Government, market and social governance have their respective characteristics, and combined strength should be cohered to play the advantages of government leading, social autonomy and market harmony with cooperation, thus to promote benign operation of social governance.

To realize compound governance, it is to establish the social governance system with government responsibility, social cooperation, public participation and legal security. It is to integrate the multivariate subjects of social governance into a compound subject of governance to play their respective advantages, form combined strength of governance and ensure multivariate subjects of social governance to be in their respective place, make their respective efforts and bring out the best in each other, thus to form the social governance layout of co-development, co-governance and sharing.

\section{OpPortunities Faced in SOCIAL GOVERnance}

\section{INNOVATION UNDER THE BACKGROUND OF GLOBALIZATION}

In the era of various challenges as well as rapid development of world multi-polarization, economic globalization, cultural diversification, governance diversity and information modernization, the new social governance layout of China led by the idea of socialism with Chinese characteristics in the new era is not only the new start for the new march of further development of China, but it also shows the sensitivity of China to the change of the global order. In such time, social governance innovation will change accordingly in terms of content, method and driving force, and it determines that social governance innovation is of greater significance in general.

Social governance innovation should not only respond to the development tide of government internationalization, but also adapt to the need for development of socialist market economy and maintain the interests of China with the characteristics of Chinese governance.

\section{A. Construct Scientific and Reasonable Governance Mechanism}

The key to strengthening and innovation of social governance lies in system innovation. Establishing the system and mechanism meeting the need of modern social governance is an inevitable path for improving and perfecting the social governance layout of co-development, co-governance and sharing. In this process, important content urgent to be solved and improved includes construction of the mechanism preventing and relieving social conflicts, social security control system, social psychological service system and community governance system as well as establishment of full-chain mechanism of public participation in major affairs, interactive mechanism with government leadership and social cooperation and legalization mechanism with legal system as the security.

\section{B. Foster Multivariate and Cooperative Subjects of \\ Governance}

Such characteristics shown in modern social governance as complexity of issues, diversity of demand, multi-dimension of value and polymorphism of forms objectively mean that neither the government and the society nor the market can 
settle the endless social issues unilaterally; instead, the governance subject of multivariate cooperation must be fostered to jointly govern the complicated social issues, thus to improve the predictability, accuracy and efficiency of social governance. Therefore, we should promote transformation of the government from an all-powerful and controlling government to a service-oriented government, encourage and support social organizations and the mass to participate in social construction, and practically construct the linked, integrated and embedded cooperative governance and co-development mode of multivariate subjects.

\section{Participate in Globalized Governance in Depth, Actively} Lead the Direction of International Order Transformation

We will uphold the global governance philosophy of co-consultation, co-development and sharing to actively participate in the reform and construction of global governance system, thus to actively respond to various global challenges and maintain international and regional peace and stability. We will actively maintain the position of main channel in multilateral trade system, promote international trade and investment freedom and facilitation and say no to protectionism of all forms. China will continue to play its role as a major power of responsibility and continuously contribute China's intelligence and power to improvement of global governance.

V. Main Measures to Promote Social Governance Innovation

Social governance innovation must realize philosophy innovation first of all to treat the new issues appearing in social governance with new thoughts and new ideas. The second point is practice innovation. Practice is necessary based on good thoughts and ideas to realize continuous revision, reform and innovation in the process of practice. Another point is innovation on method. New management methods are adopted in social governance innovation to a great extent. And finally, nothings can be achieved without norms and standards. Social governance must be innovated on norms and systems to realize system innovation in terms of social activity, social production and social behaviors.

\section{A. Stably Improve the Level of Grassroots Autonomy,}

Develop Urban-Rural Community Governance

It is to perfect the grassroots autonomy mechanism to play the principal role of the public in grassroots social governance, realize the people's affairs considered by the people, handled by the people and managed by the people, and strengthen the construction of community supervision committee. At the same time, to promote social governance, we must reform the social organization management system, optimize the development environment, improve the community governance structure, clarify the authority of grassroots government and community self-governance organizations, enhance the self-governance capacity of community and harmonize the relation between community self-governance organizations and other organizations.

Therefore, sound community environment is necessary for a harmonious society, harmonious society relies on sound community governance and sound community governance must rely on innovation of governance method.

\section{B. Enhance Emergency Treatment Mechanism, Prevent Social Risks}

The key to strengthening and innovation of social governance lies in mechanism innovation and the core is people. The society may be in stability and sound order only when the relation amount people is harmonious. Social risk management and emergency treatment are key parts of social governance. To improve the socialization, legalization, intelligentization and professionalization of social governance and improve the ability to predict and prevent various risks, we must improve the emergency treatment system and social risk prevention and relieving mechanism while establishing the mechanism for social public feelings control and major public feelings emergency treatment, thus to enhance guidance of emergency events in terms of public feelings.

\section{Promote Benign Social Operation, Innovation Is}

\section{Necessary for Comprehensive Governance}

To innovate on the method of settling social conflicts and issues, rely on the grassroots service and management platform to establish the social conflict governance mechanism with participation of multiple parties, play the advantages of mass prevention and governance for timely 
settlement, we must insist combination of normal governance and dynamic treatment, promote comprehensive social governance in all aspects, foster positive social psychology and establish psychological crisis prewarning mechanism to relieve the tense social relations.

In a word, with the beginning of the new era, the contribution of China to the world economy is transforming from quantitative increase to qualitative change, and China's contribution to social governance is transforming from hard strength to soft strength, including theory, system and practice innovation of social governance. The direction of social governance innovation and development promotes the way of thinking to be characterized with comprehensiveness, innovativeness, openness, predictability, diversity and informatization. The environment and opportunity of globalized development provides new driving force and incentive for reform on social governance mode and social governance innovation and development is faced with unprecedented challenges, which forms the powerful background for reform and transformation of the governance mode.

\section{REFERENCES}

[1] Li Jingzhi. Path Option for Promoting Construction of the Human Community of Common Destiny. Theory of Socialism with Chinese Characteristics. cssn.cn. 2018.5.3. (In Chinese)

[2] Li Youmei. The World Stepping into Deep Globalization. What China May Contribute. Jfdaily.com. 2018-01-07. (In Chinese)

[3] Chen Fengying. Interpretation of Globalized Governance in Report at the 19th Party Congress: China Scheme - Contribution and Role of China in Globalized Governance. People.com.cn. 2017.12.28. (In Chinese)

[4] Tan Zhilin. Thoughts on Social Governance Innovation. China Civil Affairs. 2014. (05): 25-26. (In Chinese) 